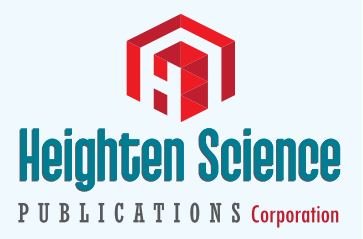

ISSN

2639-9946
*Address for Correspondence: Guillermo Padrón Arredondo, MD, Medical Service of General Direction of Police and Traffic, Petempich Avenue S/N with Mayapan Avenue, Playa del Carmen, Solidaridad, Quintana Roo, Mexico, CP. 77712, Email: gpadronarredondo@hotmail.com

Submitted: 12 January 2018

Approved: 25 January 2018

Published: 26 January 2018

Copyright: @ 2018 Arredondo GP, et al. This is an open access article distributed under the Creative Commons Attribution License, which permits unrestricted use, distribution, and reproduction in any medium, provided the original work is properly cited

Keywords: Police; Obesity; Life expectancy; Exercise, Diet, Mental health

Check for updates
Research Article

\section{Body mass index in a group of security forces (policemen). Cross- sectional study}

\author{
Guillermo Padrón Arredondo* \\ Medical Service of General Direction of Police and Traffic, Petempich Avenue S / N with \\ Mayapan Avenue, Playa del Carmen, Solidaridad, Quintana Roo, Mexico
}

\section{Summary}

Introduction: Most police officers work long hours in day and night shifts and this exposure can harm your health.

Objective: Know the Body Mass Index (BMI) of a group of policemen of both sexes chosen at random to calculate the degree of overweight / obesity of the observed population.

Material and Method: An cross-sectional study was carried out on 75 elements of the municipal police of sexes, obtaining age, height, and weight with which the corresponding Body Mass Index was obtained. Descriptive statistics were used.

Results: Measurements were taken at 75 (100\%) policemen of both of them sexes, 60 (80\%) male and 15 (20\%) female. And the following results were obtained: ideal weight $5(6.6 \%)$, overweight $21(28.0 \%)$ elements and obesity 49 (65.3\%).

Discussion: Obese workers are prone to getting sick, missing work, disability and early retirement when compared to non-obese workers. Obesity can be a predictor of early mortality; therefore, with a BMI of 30-35, life expectancy decreases from 2 to 4 years and with a BMI of $40-45$ it decreases from 8 to 10 years. In our study we found 70 (93.3\%) policemen were overweight and obese $\mathrm{BMI}>25$ ).

Conclusions: Our findings recommend the implementation of diverse programs for the improvement of the health of this labor group with a multidisciplinary team as well as the adequate physical spaces for the practice of the corresponding activities.

\section{Introduction}

Generally, police work is considered a dangerous activity so their health should be taken with the seriousness it deserves, remembering that health is the complete physical, social and mental wellbeing and not just the absence of disease. In all countries, the police play a role of primary importance to ensure the social stability required for the healthy development of society itself. This staff, when doing a specific job, has a high prevalence of obesity that is related to hypertension, hyperlipidemia, smoking and a sedentary lifestyle [1].

Most police officers work long hours in day and night shifts and this exposure can harm your health. Adverse effects of this occupation include circadian rhythm disorders, inadequate sleep, psychological disorders, metabolic diseases, type 2 diabetes mellitus and heart disease [2].

\section{Objective}

Know the Body Mass Index of a group of policemen of both sexes chosen at random to calculate the degree of overweight / obesity of the observed population. 


\section{Material and Method}

To know the degree of overweight/obesity in a population of 1000 municipal police officers, characterized by poor eating habits, lack of physical activities, harmful habits for health such as smoking and alcoholism, as well as variable work schedules of 12 and 24 continuous hours. A cross-sectional study was carried out in a sample of 75 individuals in a routine physical examination and the variables of sex, age, weight $(\mathrm{kg})$, and height $(\mathrm{cm})$ were handled, with these data the Body Mass Index was calculated (IMC) with a free internet application and blood pressure collection with Nebucor electronic equipment. Descriptive statistics was used.

\section{Results}

A total population of 1000 individuals was taken from a sample of $75(7.5 \%)$ policemen of both sexes, 60 (80\%) male and 15 (20\%) female. And the following results were obtained: Ideal weight $(18.5-25)=5(6.6 \%)$ policemen, overweight (25$30)=21(28.0 \%)$ elements and with obesity $(>30)=49(65.3 \%)$. The statistical analysis is presented in table 1 . Of the total number of individuals reviewed, eight $(10.6 \%)$ presented arterial hypertension in different ranges. Table 2 Fasting glucose was not performed due to lack of reagents.

\section{Discussion}

Obesity is a prevalent disease throughout the world and can be considered a public health problem among individuals of different occupations, including police officers who are responsible for public safety. Obese workers are prone to illness, lack of work, disability and early retirement when compared to non-obese workers [3].

Obesity can be a predictor of early mortality; therefore, with a BMI of 30-35, life expectancy decreases from 2 to 4 years and with a BMI of 40-45 this expectation is reduced from 8 to 10 years. Police officers tend to consume a high-fat diet and the decrease in their physical activity is responsible for high levels of occupational stress [4]. In our study it was found that $70(93.3 \%)$ policemen were overweight and obese BMI $>25$ ). In a study by [5] found $85 \%$ of overweight and obesity in retired policemen. The current trend is the decrease of physical activity in this work group in such a way that in the study of [6] 9\% of the agents rarely exercised, $38 \%$ did it 1 to 2 days a day. week, $32 \%$ did it 3 to 4 days a week and only $21 \%$ did it 5 days or more a week. The night shift may favor harmful eating behaviors and consequently obesity among the officers when consuming too many calories through the intake of junk foods (snaks) [7].

\begin{tabular}{|c|c|c|c|r|}
\hline \multicolumn{2}{|c|}{ Table 1: Descriptive statistical analysis of 75 policemen evaluated. } \\
\hline Mesures & Age (years) & Height (cm) & Weight (kg) & BMI \\
\hline Average & 33.4 & 1.64 & 85 & 31.6 \\
\hline Median & 33 & 1.63 & 86 & 31.2 \\
Mode & 25 & - & 86 & 31.2 \\
SD & 7.8 & 0.08 & 14.7 & 4.5 \\
Minimun & 21 & 1.44 & 51 & 22.8 \\
Maximum & 58 & 1.80 & 128 & 44.2 \\
Range & 37 & - & 77 & 21.4 \\
\hline
\end{tabular}

Table 2: Hypertensive staff in a group of 75 policemen reviewed.

\begin{tabular}{|c|c|c|c|}
\hline Age & BP & CF & BMI \\
\hline 58 & $166 / 100$ & 92 & 30.86 \\
45 & $130 / 95$ & 80 & 29.76 \\
38 & $145 / 92$ & 81 & 33.18 \\
41 & $133 / 92$ & 110 & 44.27 \\
36 & $140 / 91$ & 100 & 33.62 \\
29 & $133 / 91$ & 65 & 25.1 \\
46 & $142 / 91$ & 89 & 31.89 \\
43 & $140 / 90$ & 110 & 30.10 \\
\hline
\end{tabular}


In another study by [8] in traffic agents found hyperlipidemia in 53.7\%, hyperuricemia in $46.5 \%$ and overweight / obesity in $43.4 \%$, well below what was found in this study regarding overweight / obesity. So they recommend periodic. Medical exams with the aim of promoting the health of these workers. It has also been proven that adiposity can lead to depressive states when associated with work stress [9]. Similarly, Garbarino S, [10] recommends that workers with night shifts and to avoid loss of sleep, high levels of stress and fatigue, which can lead to human errors, incidents and accidents, can have a nap between 30 to 90 minutes before starting their night work.

On the other hand, although sleep disorders are common, they can remain undiagnosed and if they are not taken care of they can adversely affect the health and safety of the police agents and also put the public at risk [11]. Found in a group of North American policemen that sleep disorders were common and were significantly associated with their health status, their performance and their own safety [12]. Report that central adiposity is related to heart disease and alcohol consumption, which in itself is a risk factor for these diseases [13]. Studied 7 behavioral variables that could be associated with obesity in police officers: cardiovascular physical activity, strength training, extension training, sleep hours, alcohol consumption, fruits, vegetables and snacks (snacks: foods rich in fat, sugar and salt) and 6 non-behavioral variables: age, health problems, family support, work hours, work stress and police support, finding a range of obesity in men of $41.9 \%$ similar to other studies, but higher than in the general US population $35.5 \%$. In such a way that they recommend equipment for cardio exercise such as treadmills, stationary bicycles, elliptical trainers, and strength training (weights). But if space is not enough passes could be given for private gyms, hiking, golf courses, bowling, roller skating, etc., baseball, basketball, and volleyball teams can also be organized for competitions with community teams, as well as incentives for all participating personnel such as bonuses, vouchers, days off or extra vacations [14]. Recommend physical-recreational activities based on the maintenance and development of the physical condition of the police officers because they found that with their application there was improvement in resistance in $1.8 \%$, speed $29.8 \%$, swimming $1.6 \%$, strength abdominal $27.8 \%$, BMI $1.5 \%$. Therefore, its usefulness is evident [15]. In their systematic review, found very few studies related to this working group, non-experimental, qualitative at the national level and quantitative at the international level, for which they recommend that more research be carried out in security work groups because of the degree of exposure to which they are exposed.

\section{Conclusions}

The findings of this study suggest the implementation of various programs to improve the health of this work group with a multidisciplinary team of doctors, nutritionists, psychologists, and physical trainer, as well as the facilities of adequate physical spaces for the practice of corresponding activities. Of the eight agents with hypertension, six presented obesity which relates overweight to high blood pressure.

\section{References}

1. Alghamdi AS, Yahya MA, Alshammari GM, Osman MA. Prevalence of overweight and obesity among police officers in Riyad City and risk factors for cardiovascular disease. Lipids Health Dis. 2017; 16: 79. Ref.: https://goo.gl/ZiWeMq

2. Gu JK, Charles LE, Burchfiel CM, Fekedulegn D, Sarkisian K, et al. Long Work Hours and Adiposity Among Police Officers in a US Northeast City. J Occup Environ Med. 2012; 54: 1374-1381. Ref.: https://goo.gl/kQ6QH1

3. Da Silva FC, Hernandez SS, Gonçalves E, Arancibia BA, Da Silva Castro TL. Anthropometric Indicators of Obesity in Policeman: a Systematic review of observational Studies. Int J Occup Med Environ Health. 2014; 27: 891-901. Ref.: https://goo.gl/mrCG8Y

4. Violanti JM, Fekedulegn D, Hartley TA, Andrew ME, Gu JK. Life expectance in police officers: a Comparison with the U.S. General Population. Int J Emerg Ment Health. 2013; 15: 217-228. Ref.: https://goo.gl/JyaQvw 
5. Ramey SL, Downing NR, Franke WD. Milwaukee police department retirees: cardiovascular disease risk and morbidity among aging law enforcement officers. AAOHN J. 2009; 57: 448-453. Ref.: https://goo.gl/Wn2ZRi

6. Richmond RL, Wodak A, Kehoe L, Heather N. How healthy are the police? A survey of life-style factors. Addiction. 1998; 93: 1729-1737. Ref.: https://goo.gl/tcb7ir

7. Nedeltcheva AV, Kilkus JM, Imperial J, Kasza K, Schoeller DA, et al. Sleep curtailment is accompanied by increased intake of calories from snacks. Am J Clin Nutr. 2009; 89: 126-133. Ref.: https://goo.gl/LqbafP

8. Yang L, Duan D, Duan C, Li Z, Liu Y. Health status analysis of Guangzhou traffic police officers in 2013. Zhonghua Lao Dong Wei Sheng Zhi Ye Bing Za Zhi. 2014; 32: 418-420. Ref.: https://goo.gl/u11umA

9. Violanti JM, Fekedulegn D, Andrew ME, Charles LE, Hartley TA, et al. Adiposity in policing: mental health consequences. Int J Emerg Ment Health. 2011; 13: 257-266. Ref.: https://goo.gl/pxsR8M

10. Garbarino S. 24-hour work: the interaction of stress and changes in the sleep-wake cycle in the police force. G Ital Med Lav Ergon. 2014; 36: 392-396. Ref.: https://goo.gl/8vxHLf

11. Rajaratman SM, Barger LK, Lockley SW, Shea SA, Wang W, et al. Sleep disorders, health, and safety in police officers. JAMA. 2011; 306: 2567-2578. Ref.: https://goo.gl/BiSgFC

12. Baughman $P$, Fekedulegn $D$, Andrew ME, Nedra Joseph $P$, Dorn MJ, et al. Central Adiposity and Subclinical Cardiovascular Disease in Police Officers. ISRN Obes. 2013. Ref.: https://goo.gl/33Ryik

13. Can SH, Hendy HM. Behavioral Variables Associated with Obesity in Police Officers. Ind Health. 2014; 52: 240-247. Ref.: https://goo.gl/Yisr6Y

14. Sandoval Jaramillo ML, Marcel Pesantez T, Carrasco Coca OR. Incidencia de las actividades físicorecreativas en la condición física de mujeres aspirantes a policías de la Provincia de Pichincha. Educ Fis Dep, Rev Dig. Buenos Aires. 2015; 20: 10.

15. Da Silva R, Matos C, Valdivia B, Cascaes F, Barbosa P. Revisión Sistemática de la Actividad Física y de la Salud de Policías. Rev Med. 2013; 21: 75-85. Ref.: https://goo.gl/hsZYsr 